\title{
PENERAPAN KONSEP RUMAH SEHAT SEDERHANA PADA BEDAH RUMAH WARGA DI DESA PAKULONAN BARAT, TANGERANG
}

\author{
Anisza Ratnasari', Mulyadi Sugih Dharsono², Abdullah Hibrawan ${ }^{3}$, Nurul Lestari Hasanuddin, \\ Mohammad Nur Afla \\ 1,3,5 Program Studi Arsitektur, Institut Sains dan Teknologi Pradita, Tangerang \\ ${ }^{2,5}$ Program Studi Teknik Sipil, Institut Sains dan Teknologi Pradita, Tangerang
}

anisza.ratnasari@pradita.ac.id, mulyadi.sugih@pradita.ac.id, abdullah.hibrawan@pradita.ac.id,

${ }^{4}$ nurul.lestari@pradita.ac.id, nur.afla@sudent.pradita.ac.id

\begin{abstract}
Abstrak
Rumah merupakan salah satu kebutuhan primer manusia yang harus memenuhi kebutuhan fisiologis dan psikologis penghuninya. Namun demikian, kebutuhan yang harus dipenuhi seharusnya tidak hanya hal tersebut, tetapi juga mencakup pemenuhan kriteria rumah sebagai rumah sehat, yaitu harus memenuhi persyaratan kesehatan dan keamanan. Desa Pakulonan Barat merupakan salah satu permukiman padat penduduk di Tangerang, dimana masih terdapat banyak hunian warga tidak layak huni. Sejalan dengan program Bantuan Stimulan Perumahan Swadaya (BSPS) dari KemenPUPR untuk mengurangi jumlah hunian tidak layak huni, institusi melalui pengabdian kepada masyarakat bersama Corporate Social Responsibility (CSR) melakukan bedah rumah warga dengan konsep rumah sehat sederhana. Hal pertama yang dilakukan adalah mengedukasi pemilik rumah tentang pentingnya rumah sehat, wawancara terbuka dilakukan untuk mengetahui konsep rumah sedat sederhana yang diharapkan penghuni serta dilanjutkan tahan pra rancangan desain rumah sehat sederhana. Harapan kedepannya, kegiatan tersebut dapat mengedukasi warga untuk menciptakan hunian layak huni yang sehat dengan material sederhana dan biaya yang ekonomis.
\end{abstract}

Kata Kunci : rumah sehat, rumah sehat sederhana, bedah rumah, hunian layak huni

\section{PENDAHULUAN}

Sandang, papan dan pangan merupakan 3 (tiga) kebutuhan fisiologis manusia yang wajib dipenuhi. Tingkat pendidikan, pendapatan, gaya hidup dan ekonomi serta pengangguran akan mempengaruhi bagaimana masyarakat memenuhi kebutuhan dasar tersebut. Banten tercatat sebagai provinsi dengan tingkat penggangguran tertinggi di Indonesia. Menurut Badan Pusat Statistik (BPS) terdapat $8,52 \%$ Tingkat Pengangguran Terbuka (TPT) pada Agustus 2018, sebuah angka yang relatif besar bila dibandingkan dengan rata-rata TPT nasional yang berada pada angka 5,34\%. Terdapat 668.740 penduduk di Provinsi Banten masih dalam kategori miskin dikarenakan PDRB per kapita Provinsi Banten yang relatif rendah, yaitu sebesar Rp. 25.397,65. Adapun kemiskinan ini juga berdampak kepada masyarakat dalam menjaga produktifitas dan kesehatan baik jasmani maupun rohani termasuk dalam hal penyediaan rumah yang layak huni. Kesehatan fisik rumah tersebut sangat erat hubungannya dengan kondisi fisik rumah, yaitu 
mampu memberikan rasa aman, nyaman dan kemudahan dalam menjalankan aktivitasnya.

Rumah menurut Undang-undang No. 1 tahun 2011 tentang Perumahan dan Permukiman, didefinisikan sebagai bangunan gedung yang berfungsi sebagai tempat tinggal yang layak huni, sarana pembinaan keluarga, cerminan harkat dan martabat penghuninya, serta aset bagi pemiliknya. Untuk menciptakan standar rumah yang layak, sehat, aman dan nyaman, rumah harus memiliki kelengkapan dasar fisik hunian yang meliputi; prasarana, sarana dan utilitas yang berfungsi untuk mendukung penyelenggaraan dan pengembangan kehidupan sosial, budaya, dan ekonomi.

Pemenuhan semua persyaratan standar tersebut akan menciptakan rumah sehat yang memungkinkan para penghuninya dapat mengembangkan dan membina fisik mental maupun sosial keluarga. Terpenuhinya standar minimal rumah sehat akan menciptakan rasa aman penghuninya. Rasa aman diwujudkan dengan struktur rumah yang kokoh, atap tidak bocor, dinding tidak lembab, lantai tidak licin dan lembab serta mudah dibersihkan. Agar tetap kering, maka lantai harus terbuat dari bahan bangunan yang tidak menghantar air tanah ke permukaan lantai / kedap air, berada lebih tinggi dari halaman luar dengan ketinggian lantai minimal $10 \mathrm{~cm}$ dari pekarangan dan $25 \mathrm{~cm}$ dari permukaan jalan. Rasa nyaman diwujudkan dengan kecukupan pencahayaan, pengaliran udara ruang yang mampu memenuhi kebutuhan oksigen, dan kelembaban di dalam ruang yang sesuai dengan suhu tubuh bagi penghuninya, serta kebutuhan ruang gerak yang cukup. Rumah yang sehat merupakan salah satu sarana untuk mencapai derajat kesehatan yang optimum.

Hal tersebut sejalan dengan konsep rumah sehat sederhana yang menyatakan bahwa sebuah rumah selayaknya; 1) memiliki tata letak ruang yang baik; 2) memiliki persediaan air bersih yang cukup untuk minum dan pemeliharaan rumah; 3) tersedia peralatan pembuangan air hujan, air kotor, sampah dan kotoran lainnya; 4) konstruksi atap rumah tidak bocor; 5) konstruksi lantai rumah harus rapat dari air dan selalu kering agar mudah dibersihkan; 6) terdapat ventilasi yang baik; serta 7) terdapat penerang alami/buatan yang cukup terang.

Rumah yang sehat tidak luput dari lingkungan yang sehat pula, berikut syarat lingkungan sehat, yaitu; a) bertempat di daerah yang tenang; b) tersedia fasilitas umum seperti, jaringan jalan penghubung, jaringan listrik, sistem penyediaan air, sistem penyediaan air bersih, sistem pembuangan air kotor, sistem pengangkutan sampah; c) terdapat fasilitas penjagaan; d) cukup jauh jaraknya dengan kompleks industri dan tempat mengganggu lainnya; e) terdapat fasilitas lapangan; serta f) terdapat fasilitas kegiatan umum seperti rumah ibadah, sekolah, rumah sakit, tempat rekreasi dan toko-toko/pasar.

Data statistik Kabupaten Tangerang pada tahun 2017 menyebutkan bahwa tidak semua rumah di Kabupaten Tangerang termasuk rumah layak huni. Tercatat bahwa $6,11 \%$ rumah masih memiliki lantai tanah, $14,97 \%$ rumah memiliki penutup atap selain genteng dan beton, $8,01 \%$ rumah tidak memiliki dinding tembok sebagai rumah layak pada umumnya. Setelah ditelisik lebih lanjut, ternyata masyarakat yang menghuni rumah dengan kondisi kurang layak dan tidak sehat ini merupakan masyarakat pra sejahtera dengan tingkat pendidikan relatif rendah dan masyarakat berpenghasilan rendah (MBR).

Untuk membenahi perumahan masyarakat berpenghasilan rendah (MBR) dengan kondisi tidak layak huni tersebut, Kementerian Pekerjaan Umum dan Perumahan Rakyat (KemenPUPR) memiliki program Bantuan Stimulan Perumahan Swadaya (BSPS) atau yang lebih dikenal sebagai Program Bedah Rumah. Direktorat Penyediaan Perumahan KemenPUPR mengganggarkan Rp. 4,28 triliun untuk penyaluran Program BSPS tahun 2019. Jumlah bantuan tersebut meningkat dibandingkan tahun 2018 lalu, yaitu Rp. 3,25 triliun. Dalam kurun 4 tahun (2015-2018), program BSPS telah menjangkau rumah layak huni sebanyak 494.169 unit, dan pada tahun 2019 program bedah rumah ini ditargetkan akan menjangkau sebanyak 206.500 unit rumah tidak layak huni.

Untuk meningkatkan kualitas program bedah rumah, pemerintah menerbitkan Keputusan Menteri PUPR Nomor 158 tahun 2019 tentang besaran nilai BSPS. Jenis kegiatan program BSPS ini terbagi menjadi 2 (dua), yaitu; 1) Pembangunan Rumah Baru Swadaya (PRBS), dengan klasifikasi pembangunan baru pengganti rumah tidak layak huni dengan besaran bantuan dana Rp. 35 juta; dan 2) Peningkatan Kualitas Rumah Swadaya (PKRS)

$$
\text { Teknologi Tepat Guna }
$$


dengan klasifikasi rumah dengan kerusakan ringan atau tidak memenuhi persyaratan kesehatan Rp. 10 juta, rumah rusak sedang Rp. 12,5 juta, dan rumah rusak berat dengan bantuan dana sebesar Rp. 17,5 juta. Bantuan disalurkan dalam bentuk bahan bangunan, dan dalam pelaksanaannyadilakukan oleh masyarakat dengan membentuk kelompok untuk memperbaiki atau membangun rumah secara swadaya atau gotong royong.

Untuk dapat menerima bantuan program BSPS, warga setidaknya harus memenuhi 7 (tujuh) kriteria, yaitu; 1) luas lantai kurang dari $72 \mathrm{~m}^{2}$; 2) atap rumah terbuat dari daun atau lainnya; 3 ) dinding rumah terbuat dari bambu atau jenis lainnya; 4) lantai tanah; 5) tidak memiliki akses ke sanitasi yang layak; 6) tidak ada akses air minum yang layak; dan 7) sumber penerangan bukan listrik. Kementerian PUPR hanya menerima usulan rumah tidak layak huni (RTLH) yang berhaka menerima bantuan BSPS dari Bupati / Walikota / Kementerian / Lembaga yang telah dilengkapi dengan lokasi desa/kelurahan yang memiliki data RTLH dan kekurangan rumah.

Keberlangsungan program BSPS, peningkatan anggaran tahunan program dan peningkatan jumlah unit rumah layak huni yang terbangun membuktikan bahwa pemerintah benarbenar serius untuk meningkatkan kualitas hidup para penerima bantuan dengan memiliki rumah yang lebih layak, sehat, aman dan nyaman.

Sejalan dengan program BSPS yang telah dicanangkan oleh pemerintah tersebut, kegiatan Pengabdian kepada Masyarakat (PkM) Program Studi Arsitektur Institut Sains dan Teknologi Pradita bekerjasama dengan Corporate Social Responsibility (CSR) PT. Summarecon Agung, Tbk., Unit Summarecon Serpong turut ambil bagian dengan berperan aktif dalam mensukseskan program tersebut. PT. Summarecon Agung, Tbk., dalam rangka memenuhi tanggung jawab sosial terhadap permukiman masyarakat sekitarnya, melakukan pembenahan warga yang tidak layak huni dengan kriteria yang telah disebutkan diatas. Terdapat setidaknya lebih dari 5 (lima) rumah tidak layak huni di Desa Pakulonan Barat, Kecamatan, Kelapa Dua yang letaknya bersinggungan langsung dengan Kawasan Summarecon Serpong.

Tim Pengabdian kepada Masyarakat (PkM) Program Studi Arsitektur Institut Sains dan
Teknologi Pradita melakukan preliminary survey untuk menjajaki rumah warga tidak layak huni (RTLH) dengan prioritas Pembangunan Rumah Baru Swadaya (PRBS), mengedukasi pemilik rumah tentang rumah sehat, hingga mengajukan prarancangan bedah rumah dengan konsep rumah sehat sedangkan tim Corporate Social Responsibility (CSR) PT. Summarecon Agung, Tbk., bertanggungjawab dalam pembangunan rumah tersebut.

\section{METODE}

Untuk mewujudkan program bedah rumah dengan konsep hunian sehat sederhana yang sesuai dengan kebutuhan penghuni rumah, langkah-langkah sistematis kegiatan yang dilakukan dibagi menjadi 3 (tiga), yaitu; 1) mengedukasi pemilik rumah tentang pentingnya rumah sehat; 2) mewawancarai pemilik rumah tentang konsep rumah sehat sederhana yang diidamkan; 3) menyajikan prarancangan desain bedah rumah dengan dengan konsep rumah sehat sederhana.

\section{HASIL DAN PEMBAHASAN}

Desa Pakulonan Barat merupakan permukiman padat penduduk yang bersinggungan langsung dengan Kawasan Summarecon Serpong. Rata-rata mata pencaharian penduduknya adalah buruh dan sector informal lainnya, Berdasarkan preliminary survey terdapat setidaknya 5 (lima) rumah warga yang kurang layak pada setiap RW nya. Berdasarkan 7 (tujuh) kriteria penerima program bantuan-serupa BSPS, tim memutuskan bahwa rumah Bapak Taufick yang beralamat di Jalan K.H. Musa 2 No.36, Kampung Rumpak Sinang, Desa Pakulonan Barat yang mendapatkan prioritas bantuan bedah rumah. 


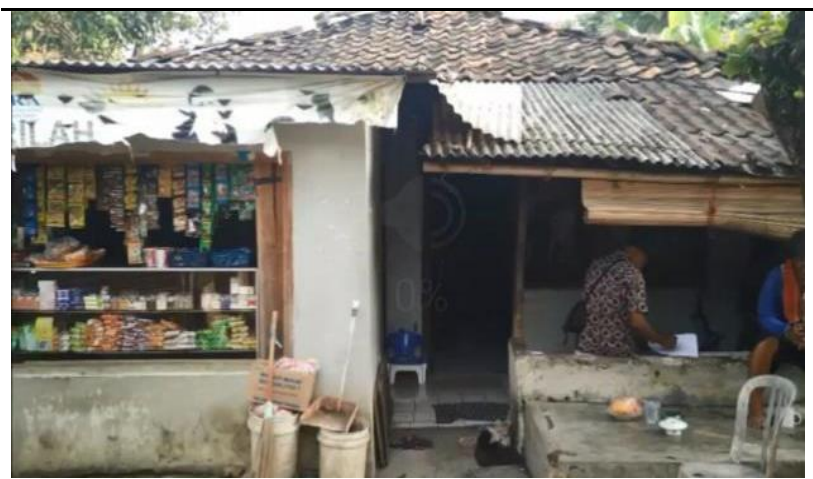

Gambar 1. Kondisi eksterior rumah bapak Taufick

Berdasarkan observasi awal, kondisi rumah Pak Taufick hanya memiliki luas kurang dari $60 \mathrm{~m}^{2}$, lantai setengah tanah dan plester, dinding semi permanen (bata dan papan), penutup atap genting dengan rangka atap bambu yang hampir roboh serta tidak memiliki MCK yang layak. Hampir tiap ruang yang ada tidak mendapatkan pencahayaan dan penghawaan alami, lembab dan tidak terawat. Bila diklasifikasikan menurut program BSPS, rumah ini layak mendapatkan jenis program Pembangunan Rumah Baru Swadaya (PRBS), dengan klasifikasi pembangunan baru pengganti rumah tidak layak huni dengan besaran bantuan dana Rp. 35 juta.

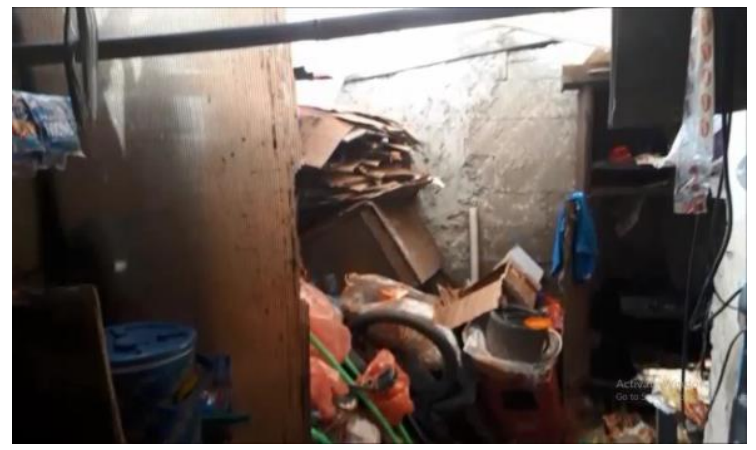

Gambar 2. Kondisi eksisting dapur

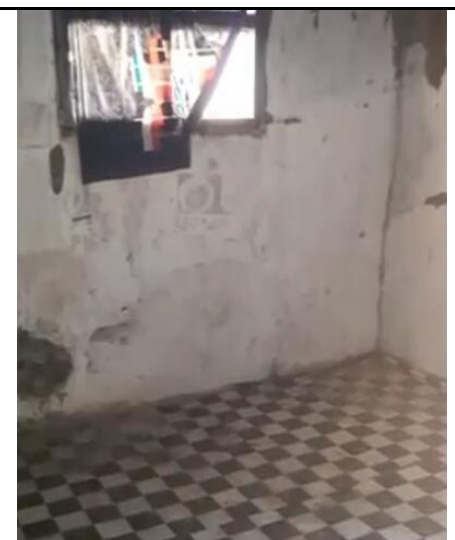

Gambar 3. Kondisi lantai interior rumah pak Taufick

Pelaksanaan bedah rumah warga ini dibagi menjadi 2 (dua) tahap. Tahap 1 adalah pra-konstruksi yang dilaksanakan Tim PkM Institut Sains dan Teknologi Pradita. Pada tahap ini dilakukan 2 (dua) kegiatan, yaitu; a) edukasi rumah sehat; b) prarancangan rumah sehat berbasis persipatori. Tahap 2, yaitu pelaksanaan bedah rumah yang dilaksanakan oleh Tim CSR PT. Summarecon Agung, Tbk. Tahap 2 ini merupakan rangkaian dari tahap 1 yang sudah dilaksanakan sebelumnya. Berdasarkan konsep rumah sehat berdasarkan parsipatori pemilik rumah, Tim CSR akan melakukan pekerjaan fidiknya, yaitu mengerjakan renovasi atau perbaikan rumah pak Taufick sesuai desain.

\section{Edukasi Konsep Rumah Sehat}

Hal pertama yang dilakukan tim PkM adalah mengunjungi rumah Bapak Taufick untuk melakukan wawancara tentang pentingnya rumah sehat. Rupanya konsep rumah sehat adalah sesuatu yang mewah bagi Bapak Taufick dan keluarga, karena beliau beranggapan dengan keterbatasan dana dan lahan yang ada tidak memungkinkan baginya untuk menciptakan hunian ideal yang dimaksud.

Tabel 1. Aspek Rumah Sehat Sederhana

\begin{tabular}{l|c|c}
\hline Aspek Rumah Sehat & Paham & Tidak \\
\hline Memiliki tata letak ruang yang baik & - & $\sqrt{ }$ \\
\hline $\begin{array}{l}\text { Memiliki persediaan air bersih yang } \\
\text { cukup untuk minum dan pemeliharaan } \\
\text { rumah }\end{array}$ & - & $\sqrt{ }$ \\
\hline $\begin{array}{l}\text { Memiliki peralatan pembuangan air } \\
\text { hujan, air kotor, sampah dan kotoran } \\
\text { lainnya }\end{array}$ & $\sqrt{ }$ & - \\
\hline
\end{tabular}

Teknologi Tepat Guna 


\begin{tabular}{l|c|c}
\hline Konstruksi atap rumah tidak bocor & $\sqrt{ }$ & - \\
\hline $\begin{array}{l}\text { Konstruksi lantai rumah harus rapat } \\
\text { dari air dan selalu kering agar mudah } \\
\text { dibersihkan }\end{array}$ & $\sqrt{ }$ & - \\
\hline Terdapat ventilasi yang baik & - & $\sqrt{ }$ \\
\hline $\begin{array}{l}\text { Terdapat penerang alami/buatan yang } \\
\text { cukup terang }\end{array}$ & - & $\sqrt{ }$ \\
\hline
\end{tabular}

Edukasi yang dilakukan terhadap keluarga ini meliputi definisi rumah sehat yang tidak harus mahal, dapat memanfaatkan berbagai alternatif material untuk menciptakan hunian sehat. Berdasarkan tabel 1 diatas pak Taufick sepenuhnya paham bahwa rumah seharusnya memiliki konstruksi yang kokoh baik itu, atap, dinding dan lantai. Namun karena kondisi ekonomi keluarga, pak Taufick belum mampu menciptakannya. Sedangkan untuk kriteria lainnya, pak Taufick dan keluarga menyatakan belum memahami bahwa sebuah rumah harus memiliki tata letak rumah, ventilasi maupun pencahayaan alami yang cukup.

\section{Pra-rancangan Rumah Sehat Sederhana Berbasis Parsipatori}

Berangkat dari edukasi yang telah dilakukan, pak Taufick menyadari arti pentingnya menciptakan hunian yang sehat meskipun sangat sederhana. Tim PkM Program Studi Arsitektur melalui wawancara yang dilakukan terhadap seluruh anggota keluarga melalukan pendekatan tentang desain rumah yang menjadi keinginan seluruh anggota keluarga.

Berdasarkan gambar dapat disimpulkan bahwa semua anggota keluarga mengharapkan perbaikan menyeluruh untuk rumah mereka, terutama tentang ketersediaan air bersih, kamar mandi yang bersih, ruang dengan ventilasi dan pencahayaan yang baik dan tidak lembab.

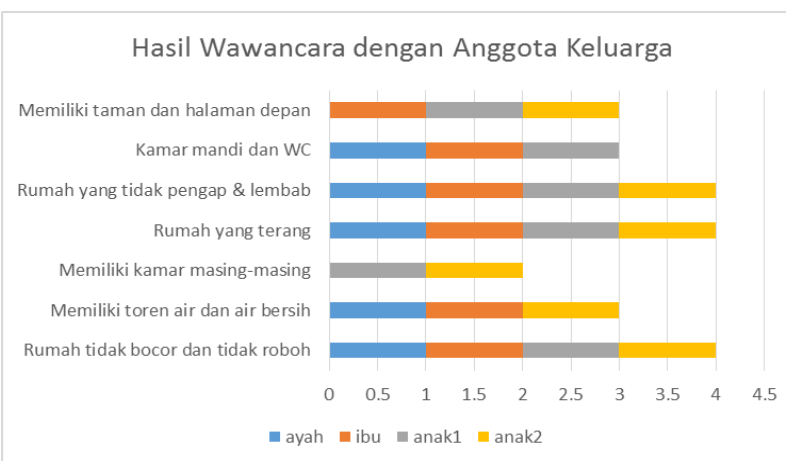

Gambar 4. Wawancara dengan anggota keluarga pak Taufick

Tim PkM menterjemahkan hasil wawancara tersebut dalam konsep desain rumah sehat yang mereka inginkan. Langkah awal tim menyerahkan draf konsep berupa zonasi rumah. Tanpa menambah luasan lahan yang dimiliki dan perletakan system plambing serta sanitasi, tim melakukan zonasi ruang untuk mendapatkan tata letak ruang yang baik, dengan tujuan semua ruang di dalam rumah mendapatkan pencahayaan alami dan penghawaan yang baik. Tahap kedua, draft zonasi tersebut disampaikan kepada pak Taufick guna mendapatkan masukan apakah sudah sesuai dengan rancangan yang di maksud. Tahap berikutnya adalah konsep pra-rancangan rumah, menentukan letak dan luas bukaan, yaitu pintu, jendela, skylight, bovenlight dan angin-angin untuk ventilasi udara dan sunlight harvesting.

\section{Pekerjaan Konstruksi}

Tahap pekerjaan konstruksi dimulai dari pekerjaan plambing dan sanitasi, pekerjaan dinding, pekerjaan lantai, pekerjaan kusen, pekerjaan rangka atap dan finishing pekerjaan. 


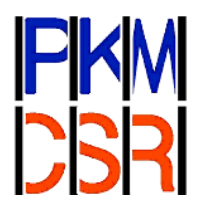

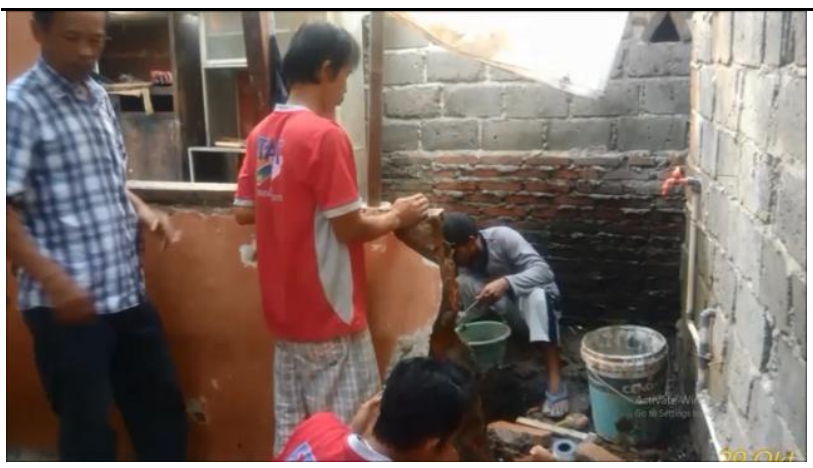

Gambar 5. Pekerjaan plambing dan sanitasi

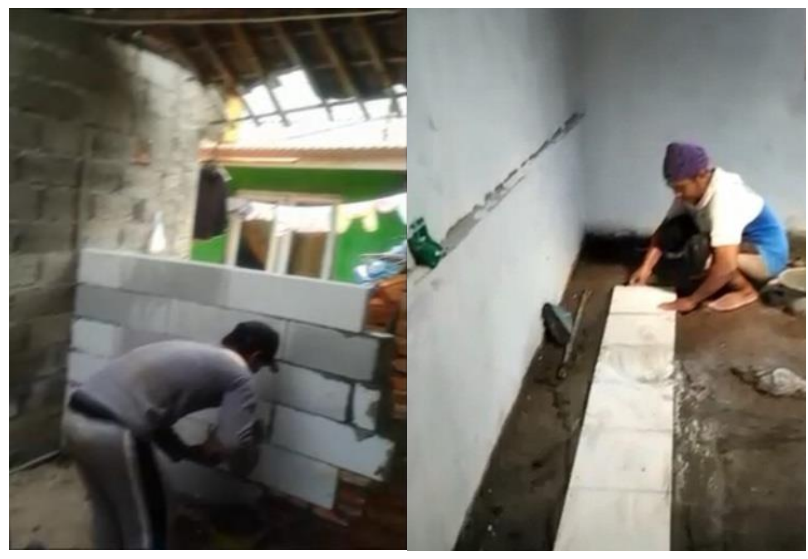

Gambar 6. Pekerjaan pemasangan dinding bata ringan (kiri) dan pemasangan keramik lantai kamar (kanan)

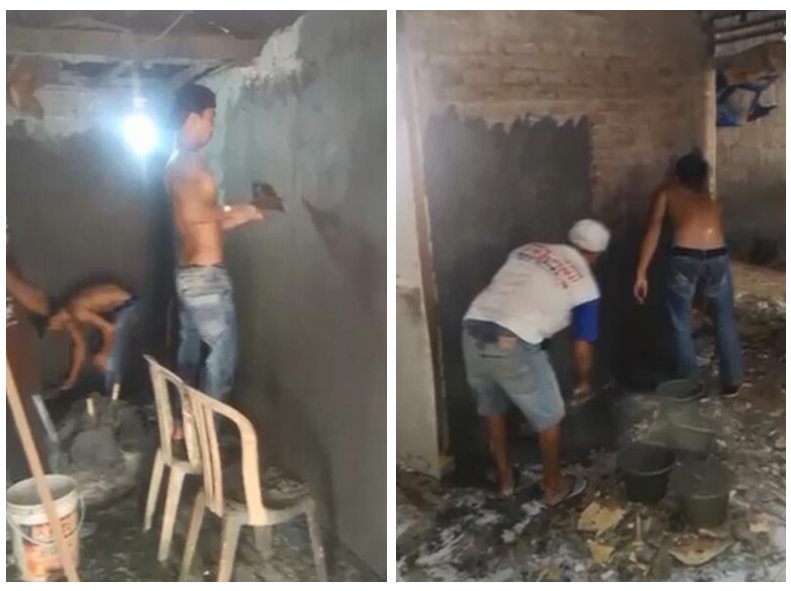

Gambar 7. Pekerjaan plester dinding

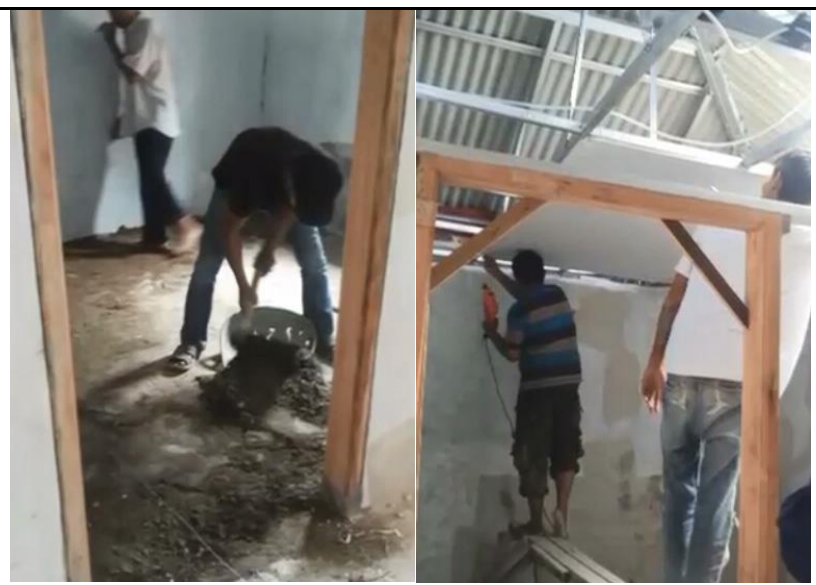

Gambar 8. Pekerjaan pemasangan kusen

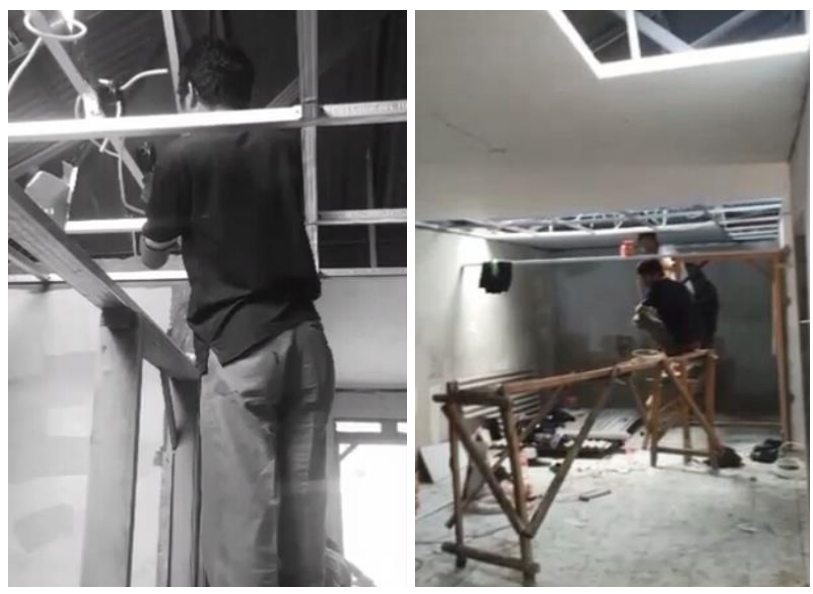

Gambar 9. Pekerjaan pemasangan rangka plafon (kiri) dan pemasangan plafon (kanan)

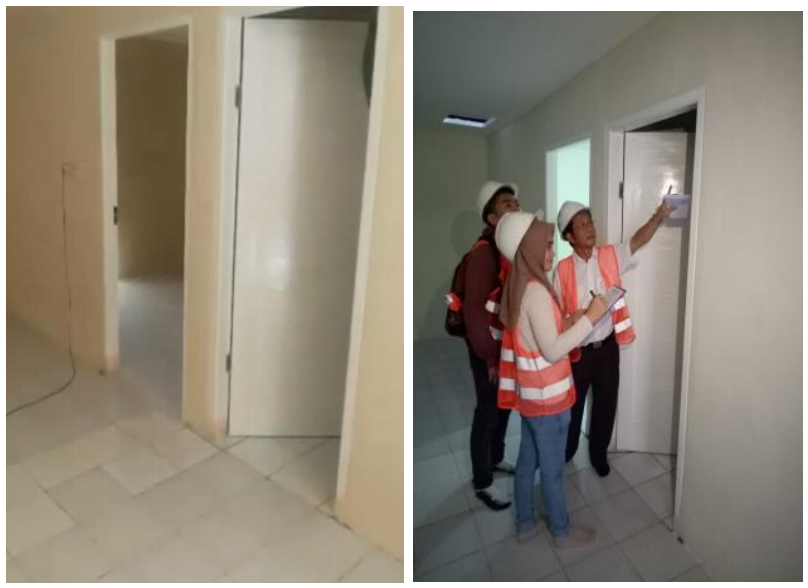

Gambar 10. Interior rumah pak Taufick (kiri) dan pengecekan kualitas pekerjaan oleh Tim PkM (kanan) 


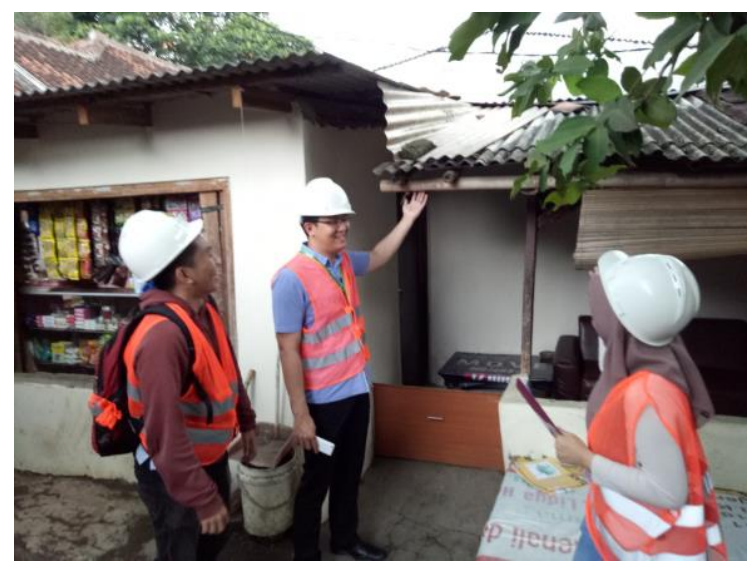

Gambar 11. Pengecekan hasil pekerjaan oleh Tim PkM (tampak depan)

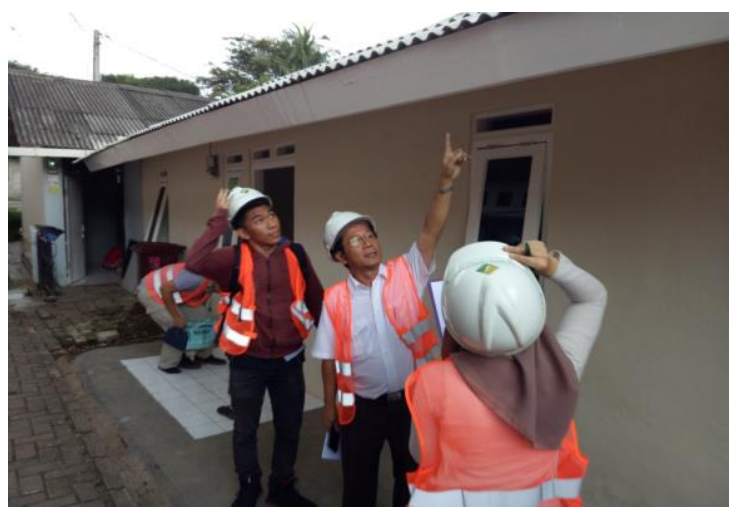

Gambar 12. Pengecekan hasil pekerjaan oleh Tim PkM (tampak samping)

\section{KESIMPULAN}

Serangkaian kegiatan yang dilakukan Tim PKM-CSR Institut Sains dan Teknologi Pradita dan PT. Summarecon Agung, Tbk., ini terlaksana baik tanpa sinergi dan kerjasama yang kuat dari akademisi dan korporasi dalam rangka mensukseskan program pemerintah BSPS untuk meningkatkan kualitas hidup para penerima bantuan dengan memiliki rumah yang lebih layak, sehat, aman dan nyaman. Ucapan terimakasih juga kami sampaikan atas dukungan dari pihak-pihak yang telah terlibat dalam perencanaan program, pelaksanaan maupun penyusunan laporan. Kegiatan PKM-CSR ini masih jauh dari kesempurnaan, oleh karena itu penulis mengharapkan partisipasi berupa saran dan masukan yang membangun dari semua pihak demi penyempurnaan kegiatan serupa.

Agar keberlanjutan kegiatan yang mendukung program pemerintah ini terlaksana dengan baik, beberapa saran yang dapat kami berikan adalah sebagai berikut; 1) edukasi warga tentang pentingnya menciptakan rumah sehat sederhana; 2) sosialisasi dari pemerintah tentang program bedah rumah warga untuk mengurangi angka hunian tidak layak huni.

\section{UCAPAN TERIMAKASIH}

Terselenggaranya kegiatan Pengabdian kepada Masyarakat $(\mathrm{PkM})$ ini tidak terlepas dari dukungan Corporate Social Responsibility (CSR) PT. Summarecon Agung, Tbk., yang telah bekerja sama dan memberikan kontribusi dalam pelaksanaan program bedah rumah ini.

Rasa terimakasih kami sampaikan kepada, Prof. Richardus Eko Indrajit selaku rektor dan Prof. Harianto Hardjasaputra selaku wakil rektor 1 bidang akademik Institut Sains dan Teknologi Pradita yang telah memberikan dukungan, kebijakan dan pengarahan dalam penyusunan program kegiatan PKM-CS (Pengabdian Kepada Masyarakat dan Corporate Social Responsibility).

Ucapan terima kasih juga kami sampaikan kepada segenap dosen dan mahasiswa Program Studi Arsitektur serta Bapak Mulyadi Sugih Dharsono selaku Ketua Program Studi Teknik Sipil Institut Sains dan Teknologi Pradita yang telah mendanai kegiatan ini pengabdian kepada masyarakat ini.

Tidak lupa juga kami mengucapkan terimakasih kepada PT. Summarecon Agung, Tbk., yang telah bekerja sama dan memberikan kontribusi dalam pelaksanaan program bedah rumah ini. Tanpa dukungan dana dan sponsor dari korporasi yang merupakan bentuk kegiatan Corporate Social Responsibility (CSR), program bedah rumah warna ini mustahil terlaksana

Demikian ucapan terima kasih ini kami sampaikan kepada segenap pihak yang tidak dapat kami sebutkan satu persatu demi tercapainya

$$
\text { Teknologi Tepat Guna }
$$


keberhasilan program PKM-CSR. Harapan kedepannya ada kerjasama dan sinergi yang lebih baik antara akademisi dan korporasi sehingga program-program serupa dapat terus dijaga keberlanjutannya demi mendukung program pemerintah untuk mewujudkan hunian yang layak huni bagi masyakat.

\section{REFERENSI}

Badan Peneliti dan Pengembangan, Kementerian Pekerjaan Umum dan Perumahan Rakyat (2006). Dasar-dasar Rumah Sehat. Jakarta: Menteri Pekerjaan Umum dan Perumahan Rakyat

Gunawan, R. (2009). Rencana Rumah Sehat.
Yogyakarta: Penerbit Kanisius.

Sabaruddin, A., Hartini, Hermawan Y. (2011). Rumah Sehat. Bandung: Pusat Penelitian dan Pengembangan Permukiman - Balitbang Kementerian Pekerjaan Umum.

Undang - Undang Republik Indonesia Nomor 1 Tahun 2011 tentang Perumahan dan Permukiman.

Keputusan Menteri Pekerjaan Umum dan Perumahan Rakyat nomor 158 Tahun 2019 tentang besaran nilai anggaran BSPS.

https://www.pu.go.id/berita/view/17278/tah un-2019-kementerian-pekerjaan-umum-danperumahan-rakyat/ 